COMMENT. Neuroinfectious disease is an expanding field of investigation, both in acute and in chronic disorders. The role of viral meningitis in the cause of epilepsy has received increasing attention (Ped Neur Briefs 2008;22:75). Maternal infection during pregnancy increases the risk of epilepsy in the offspring (Ped Neur Briefs 2008;22:45). Brain inflammation has a role in epileptogenesis (Choi J, Koh S. Yonsei Med J 2008;49:118).

\title{
CONTINUOUS EEG MONITORING IN CRITICALLY ILL PATIENTS WITH CNS INFECTIONS
}

The prevalence, predictors, and clinical significance of electrographic seizures (ESz)

or periodic epileptiform discharges (PEDs) recorded during continuous electroencephalographic monitoring in critically ill patients with CNS infections were evaluated in a study at Columbia University Medical Center, New York, NY. Of 42 patients (mean age 39 years; range 0-82) identified between 1996 and 2007, 27 (64\%) had viral infection, $8(18 \%)$ bacterial, and $7(17 \%)$ fungal or parasitic infections. Electrographic seizures were recorded in 14 (33\%) patients and PEDs in 17 (40\%). Either ESz or PEDs were recorded in $20(48 \%)$ patients. Five $(36 \%)$ of the 14 patients with ESz had clinical seizures. PEDs and viral infection were independently associated with ESz $(\mathrm{P}=0.001$ and 0.02 , respectively). ESz $(\mathrm{P}=0.02)$ and $\mathrm{PEDs}(\mathrm{P}=0.01)$ were independently associated with poor outcome at discharge. Thirteen (31\%) patients had severe disability, 3 were in coma or persistent vegetative state, and 5 died. (Carrera E, Claassen J, Oddo M, Emerson RG, Mayer SA, Hirsch LJ. Continuous electroencephalographic monitoring in critically ill patients with central nervous system infections. Arch Neurol Dec 2008;65:1612-1618).

COMMENT. Continuous EEG monitoring should be considered in patients with CNS infections and especially viral infection. Since electrographic seizures (ESz), recorded in $33 \%$ of the patients in this study, are associated with poor outcome, further studies are required to determine whether the ESz should be treated. The neurotropism and more extensive parenchymal damage after viral encephalitis compared to bacterial meningitis may explain the higher incidence of ESz with CNS viral infections.

\section{NEUROMUSCULAR DISORDERS}

\section{BRACHIAL PLEXUS PALSY AND CORTICAL DYSPLASIA}

Researchers at the Miami Children's Hospital report 2 infants with obstetrical brachial plexus palsy, ipsilateral leg weakness, and contralateral motor cortical dysplasia. Case 1, an 18-month-old girl presented for evaluation of a left brachial plexus palsy that followed a delivery complicated by shoulder dystocia. At 3 months, the left leg moved less and was shorter than the right. At 6 months, following a febrile seizure, a head CT revealed a smaller right hemisphere, and an EEG showed vertex spikes. Right-sided motor cortex dysplasia was diagnosed by MRI at 11 months of age and confirmed at 24 months. MRI of the brachial plexus and spinal cord were normal. At age 18 months, neurologic examination showed restricted left arm abduction and elbow flexion, decreased left biceps and 